\title{
EMPATÍA Y PERSPECTIVA: UNA CONCEPCIÓN SMITHIANA DE LA HUMANIDAD*
}

\author{
Sam Fleischacker \\ Universidad de Illinois, Chicago
}

\begin{abstract}
Resumen: En su Teoría de los sentimientos morales, el escocés Adam Smith desarrolló una concepción de la empatía que nace no sólo del acto de ponerse en la situación del otro, sino del acto de tratar de compartir su perspectiva de esta situación. Como consecuencia de ello, postula este artículo, Smith tendría una mirada del yo más compleja que la de Kant o Hume, sus contemporáneos, ya que fue capaz de ver el lugar que ocupan los sentimientos y cómo éstos nos ayudan a entender aquello que los hombres compartimos y aquello que nos hace únicos y distintos. El artículo, por último, aventura algunas de las consecuencias históricas que derivaron de esta visión.
\end{abstract}

Palabras Clave: empatía, perspectiva, Adam Smith, David Hume, Immanuel Kant, derechos humanos.

RECIBIDO: septiembre 2017; ACEPTADO: octubre 2017.

SAm Fleischacker. PhD en filosofía por Yale University. Profesor en la Facultad de Filosofía en la Universidad de Illinois en Chicago. Su último libro es Kant's Questions: What is Enlightenment? (Nueva York: Routledge, 2013). Email: fleischert@ sbcglobal.net.

* Este artículo será presentado en The Adam Smith Chile Conference, a realizarse en la Universidad Adolfo Ibáñez, sede Viña del Mar, el 12 y 13 en enero de 2018. Corresponde a una versión abreviada del capítulo 2 del libro Being Me Being You: An Essay in Smithian Empathy, que publicará University of Chicago Press en 2019. El autor y la traductora Sandra Cifuentes Dowling agradecen a University of Chicago Press por permitir su publicación en castellano. 


\section{EMPATHY AND PERSPECTIVE A SMITHIAN CONCEPTION OF HUMANITY}

ABSTRACT: In his Theory of Moral Sentiments, the Scottish thinker Adam Smith developed a conception of empathy as arising from the act not just of putting oneself in someone else's situation, but of trying to share their perspective on that situation. This article argues that Smith thereby developed a more complex view of the self than his contemporaries Kant and Hume, as he was capable of seeing the role played by sentiments and the way they help us discriminate what we share with others from what makes us distinctive and unique. Lastly, the article attempts to show some of the historical consequences deriving from this outlook.

KeYwords: empathy, perspective, Adam Smith, David Hume, Immanuel Kant, human rights.

RECEIVED: September 2017; ACCEPTED: October 2017.

a inspiración del presente ensayo son las obras del filósofo del siglo XVIII Adam Smith. Debo aclarar, sin embargo, que Smith nunca empleó en ellas la palabra "empatía" (empathy), acuñada, en inglés, recién a comienzos del siglo XX. Smith y David Hume se refirieron, más bien, al término "simpatía" (sympathy) para aludir en esencia a lo que nosotros entendemos actualmente por "empatía", esto es, una manera de compartir sentimientos de otros sin que ello signifique, necesariamente, que tales sentimientos lleguen a preocuparnos. ${ }^{1}$

Teniendo ello presente, dediquémonos a estudiar el debate producido entre Hume y Smith sobre la naturaleza de la simpatía. Hume interpreta la simpatía como transmitida de una persona a otra principalmente por medio del contagio: yo "agarro" tus sentimientos mediante tus expresiones. Tú pareces estar triste, por lo tanto, yo me siento triste; si te muestras alegre, ello me alegra. Sin embargo, no queda del todo claro cómo opera exactamente este mecanismo de contagio para Hume. Algunas veces indica que uno puede inferir lo que el otro siente a partir

${ }^{1}$ Respecto al sentido del significado de la palabra simpatía para Adam Smith, ver Leonidas Montes, "Self-Interest and the Virtues", en Adam Smith: His Life, Thought, and Legacy, editado por R. Hanley (Princeton: Princeton University Press, 2016), 140-1. 
de sus expresiones; ${ }^{2}$ otras veces, pareciera no existir la intermediación de esta inferencia y los sentimientos del otro o la manera en que éste los expresa generan un impacto directo en mí. ${ }^{3}$ En cualquier caso, acabamos captando una idea básica de los sentimientos del otro. Luego, asociamos esta idea, en nuestra imaginación, con la idea del yo —nos imaginamos sintiendo lo que el otro está sintiendo- $-\mathrm{y}$, de este modo, llegamos a "experimentar" el sentimiento ajeno.

Para Adam Smith, en cambio, sentimos lo que el otro siente proyectándonos en su situación e imaginando cómo nos sentiríamos si estuviéramos en su lugar. ${ }^{4}$ Smith admite, sin embargo, que en ocasiones "puede parecer" que la simpatía emerge por mero contagio. En efecto, manifestaciones intensas de júbilo o de pesar pueden animar o ensombrecer el estado de ánimo de quien las observa. ${ }^{5}$ Pero incluso en tales casos, afirma Smith, el júbilo y el pesar se transmiten "porque nos sugieren la idea general de cierta buena o mala fortuna experimentada por la persona en la cual observamos tales manifestaciones" (TMS 11, I.i.1.8). Así, nos imaginamos a nosotros mismos en la situación de haber experimentado la buena o mala fortuna. ${ }^{6}$

${ }^{2}$ David Hume, A Treatise of Human Nature, editado por L.A. Selby-Bigge y P.H. Nidditch, segunda edición (Oxford: Clarendon, 1978), 319 y 516.

${ }^{3}$ Hume, A Treatise, 317, 386, 576, 592 y 605. Analizo las diversas interpretaciones que ofrece Hume para la simpatía en "Sympathy in Hume and Smith: A Comparison, Critique, and Reconstruction", publicado en Intersubjectivity and $\mathrm{Ob}$ jectivity in Adam Smith and Edmund Husserl, editado por C. Fricke y D. Føllesdal (Múnich: De Gruyter, 2013).

4 "Simulación" podría ser mejor palabra que "proyección", pero lamentablemente ésta tiende a asociarse con la teoría de la simulación. En tal sentido, no sería posible hacer coincidir a Hume y a Smith con el debate contemporáneo entre los "teóricos de la teoría" y "los teóricos de la simulación". Véase mi trabajo "Sympathy in Hume and Smith".

5 "En algunas ocasiones, la simpatía parece surgir meramente de la observación de cierta emoción en el otro. Las pasiones pueden parecer como permeadas entre los hombres de manera instantánea y precedente a cualquier clase de información sobre lo que las provocó en la persona principalmente afectada". Smith, The Theory of Moral Sentiments, editado por D.D. Raphael y A.L. Macfie (Oxford: Clarendon, 1976), 11. Tal como se acostumbra, de ahora en adelante me referiré a esta obra como TMS.

${ }^{6}$ De acuerdo con esta línea de pensamiento, entiendo que Smith rechaza por completo la explicación del contagio que ofrece Hume, admitiendo simplemente que dicha explicación parece correcta en esos casos concretos, pero considerándolos incluso a ellos como cuestión de proyección o simulación. Sin embargo, la mayoría de los intelectuales lo considera un teórico de la simulación que acepta la postura del contagio como correcta en ciertas ocasiones. Esta diferencia no tiene mayor importancia para el presente análisis. 
Además, hasta en casos de júbilo y pesar - $-\mathrm{y}$ ciertamente con respecto a la mayoría de los demás sentimientos - no simpatizamos en ningún grado de profundidad con el otro a menos que conozcamos más acerca de su situación:

Lamentos generales, que no expresan otra cosa que la angustia de quien sufre, provocan más curiosidad por conocer detalles sobre su situación... que algún grado de simpatía auténticamente sensible. La primera pregunta que nos surge es: ¿qué ha ocurrido? Hasta que esa pregunta no sea respondida, a pesar de sentirnos inquietos por la vaga idea que tenemos sobre el infortunio del afectado y, todavía más, por torturarnos con conjeturas sobre lo que pudiera realmente estar ocurriendo, nuestra consideración hacia el otro no será muy considerable. (TMS 11-12, I.i.1.9)

Smith concluye afirmando: "La simpatía no surge tanto de nuestra observación del dolor generado, como de la situación que lo ha provocado" (TMS 12, I.i.1.10).

La principal diferencia entre Hume y Smith a este respecto es que para Smith — no así para Hume - puede ocurrir muy frecuentemente que uno sienta algo distinto a lo que siente el sujeto afectado cuando simpatizamos con él. Hume admite que esto a veces puede pasar, por ejemplo, cuando nos sentimos avergonzados por una persona que está haciendo el ridículo en público sin darse cuenta. Pero para él se trata de un caso complejo de explicar, mientras que para Smith dicha explicación surge espontáneamente de la forma en que la simpatía funciona en casos paradigmáticos. Si observo que una persona es insultada, imagino que me sentiría molesto en su situación, aunque no tan molesto como la propia persona insultada pareciera estar o, quizás, más molesto incluso que ella misma, ya que podría admirar su estoicismo o pensar que no se respeta suficientemente a sí misma. Si observo que alguien es premiado por algo, creo que me sentiría menos satisfecho conmigo mismo estando en su caso o, por el contrario, mucho más satisfecho de lo que la persona en cuestión pareciera estar. La simpatía smithiana abre una brecha entre los sentimientos que tenemos por otra persona y los sentimientos que ella tiene por sí misma. Por lo tanto, resulta una suerte de logro si la persona que simpatiza y la persona simpatizada son capaces de alcanzar cierta armonía o concordancia de sentimientos. 
2.

Un segundo aspecto a considerar de la visión smithiana de la simpatía es que ésta consiste no sólo en sentir lo que el otro podría estar sintiendo, sino también en ser sensible a cómo las cosas se sienten específicamente para él o ella. Stephen Darwall explica la diferencia entre ambas dimensiones. La primera de ellas puede ejemplificarse con la conocida situación presentada por Daniel Kahneman y Amos Tversky:

El señor Crane y el señor Tees tenían programado despegar del aeropuerto a la misma hora, pero en vuelos diferentes. Viajaron por la ciudad desde su lugar de origen en la misma limusina, ambos se vieron atrapados en el tráfico y llegaron al aeropuerto 30 minutos después de la hora de despegue programada. Al señor Crane se le informó que su vuelo había despegado a la hora establecida. Al señor Tees, que su vuelo se retrasó y que había despegado apenas cinco minutos antes de su llegada al aeropuerto. ${ }^{7}$

La mayoría de las personas (96 por ciento de los encuestados por Kahneman y Tversky) responde ante este escenario asumiendo que Tees estaría mucho más molesto que Crane, pues cada cual cree que, en el lugar de Tees, lo habría estado. Muy pocos piensan lo que en términos generales significaría ser Tees o ser Crane; simplemente se imaginan a sí mismos en sus respectivas situaciones. ${ }^{8}$ La historia podría ser contada con tu nombre en lugar de los nombres de los personajes del estudio y el resultado sería exactamente igual. Por el contrario, nuestra reacción sería muy distinta si se nos dijera algo específico sobre la situación de

${ }^{7}$ D. Kahneman y A. Tversky, "The Simulation Heuristic”, en Judgment under Uncertainty, editado por D. Kahneman, P. Slovic y A. Tversky (Cambridge: Cambridge Univ. Press, 1982); citado en Stephen Darwall, "Empathy, Sympathy, Care", Philosophical Studies 89, n. ${ }^{\circ}$ 2-3 (1998): 268.

${ }^{8}$ Tal como Peter Goldie puntualiza, no se nos ofrece una "caracterización" de Crane o Tees, lo que significa que el experimento no involucra ni empatizar con el otro ni imaginarse en el lugar del otro. "El proceso consiste, básicamente, en imaginarnos a nosotros mismos representando dos relatos distintos" (Goldie, The Emotions (Oxford: Clarendon Press, 2002), 200n). Concuerdo con dicho postulado, aunque me parece que el ejercicio sí implica imaginarse en el lugar del otro. Goldie es extraordinario a la hora de proponer detalladas taxonomías de las emociones y de la forma en que éstas se comparten, aunque a veces puede hilar demasiado fino en sus distinciones. 
Tees - que podría llegar tarde a una boda, por ejemplo, o que no tiene prisa en llegar a destino y sí mucho que leer mientras aguarda en el aeropuerto - y luego nos preguntaran cómo sería estar en su lugar. Eso, dice Darwall, es precisamente lo que Adam Smith llama simpatía:

Si compadezco a otro por la pérdida de su único hijo, para introducirme en su dolor no debo tener en cuenta lo que yo - alguien con personalidad propia y una ocupación específica - sufriría si tuviera un único hijo que, desafortunadamente, muere, sino que debo considerar lo que yo debería sufrir si fuera efectivamente el otro, por lo tanto, no sólo debo intercambiar mis circunstancias específicas con las del otro, sino también la persona misma y el carácter. (TMS 317, VII.iii.1.4) ${ }^{9}$

Darwall nos brinda una matizada interpretación del pasaje anterior. "Consideremos la diferencia — nos dice — entre los siguientes escenarios: (a) imaginemos lo que alguien sentiría si perdiera a su único hijo y (b) imaginemos cómo sería para esa persona sentirse de esa forma". En la situación (a), dice Darwall, pensaríamos: “¿Qué tragedia tan terrible perder al hijo amado!”. En la situación (b), pensaríamos: “¿Qué tragedia tan terrible para él perder al hijo amado!". ${ }^{10}$. El segundo escenario nos exige considerar "al otro no sólo como sujeto de sentimientos acordes al caso, sino a alguien que es consciente de dichos sentimientos, de sus texturas fenomenológicas y de la pertinencia de los mismos para su vida". ${ }^{11}$ Propongo llamar a los sentimientos nacidos en el segundo escenario como "perspectivos" o "smithianos", en contraste con la empatía básica que pudiéramos sentir por Tees y Crane. La empatía smithiana implica ser consciente de que la perspectiva del otro es distinta a mi propia perspectiva y significa un intento por introducirnos en su situación a partir de dicha perspectiva. ${ }^{12}$

\footnotetext{
${ }^{9}$ Citado en Darwall, "Empathy, Sympathy, Care”, 269

${ }^{10}$ Darwall, "Empathy, Sympathy, Care”, 270 (el énfasis es mío).

${ }^{11}$ Ibídem.

${ }^{12}$ El análisis que hace Smith de la simpatía se orienta básicamente a lo que he llamado empatía; él no incorpora al término el factor de la preocupación tan integralmente como lo hace Darwall, pero sí insinúa que la empatía suele involucrar cierta disposición a preocuparse por el objeto al cual se dirige. Smith comienza su $T M S$ afirmando que existen "ciertos principios en nuestra naturaleza que hacen que la felicidad de otros nos resulte necesaria, aunque no obtengamos nada de ello salvo
} 
3.

Un tercer aspecto sobre la interpretación que hace Smith es que, para él, ser consciente de una situación de simpatía mutua resulta siempre agradable. Pero Hume critica a Smith por dicho matiz. En una carta que le envía en respuesta a la publicación de la primera edición de $L a$ teoría de los sentimientos morales, dice:

Desearía que hubieras demostrado de manera más específica e integral que toda clase de Simpatía es necesariamente Agradable... Parecería que existiese una Simpatía desagradable y otra agradable. Y, en efecto, como la Pasión Simpatética es una imagen refleja de la principal, ésta debe ser partícipe de sus Cualidades y debe ser dolorosa cuando aquella la sea... Un Sujeto malhumorado, cansado y disgustado con todo, siempre aburrido, enfermizo y quejumbroso; alguien así, evidentemente, arrojará Desánimo a la Compañía, lo que podría considerarse como una forma de simpatía, y sin embargo es desagradable... Si toda simpatía fuera agradable, un Hospital podría ser un Lugar más divertido que un Salón de Baile. ${ }^{13}$

Smith respondió a esta crítica afirmando que, aunque es efectivamente doloroso compartir el dolor de otro - difícilmente aceptaríamos "compartirlo" de cualquier otra forma-, la conciencia de saber que yo comparto los sentimientos del otro, del tipo que éstos sean, es siempre agradable. Y es esta conciencia del sentimiento compartido lo que da forma a la emoción por medio de la cual aprobamos los sentimientos ajenos:

el placer de contemplar dicha felicidad" (TMS 7, primera línea del libro). Uno de esos principios, nos señala, es la lástima o la compasión. Luego puntualiza que la simpatía fue originalmente empleada como sinónimo de lástima o compasión, pero puede actualmente usarse, "sin mayor incorrección", como un término para describir nuestra "consideración de cualquier clase de pasión ajena" (TMS 10). Parece lógico pensar que la simpatía smithiana - ya sea con el gozo, el dolor o cualquier otro sentimiento - implica una disposición a preocuparnos por la felicidad del otro, "aunque no obtengamos nada de ello, salvo el placer de contemplar dicha felicidad". Es decir, en el marco de la simpatía smithiana, somos proclives a preocuparnos por la felicidad del otro con miras a su propio bien.

${ }^{13}$ Adam Smith, Correspondence 36, en Correspondence of Adam Smith (Indianapolis: Liberty Fund, 1987), 43. 
En el acto de aprobación existen dos elementos a considerar. El primero es la pasión simpatética del espectador; el segundo, la emoción que nace de observar la perfecta coincidencia entre esta pasión simpatética y la pasión original en la persona por quien se está preocupado. Esta última emoción, que consiste en el sentimiento de aprobación, es siempre agradable y placentera. La primera de ellas, por el contrario, puede ser agradable o desagradable, dependiendo de la naturaleza de la pasión original, cuyas características debe siempre, en cierta medida, conservar. (TMS 46n, I.iii.1.9n)

La fuerza de esta respuesta parece habérsele escapado a algunos intelectuales, quienes argumentan que los sentimientos negativos del otro sumados a nuestros sentimientos negativos respecto a los sentimientos negativos del otro no pueden generar como resultado ningún sentimiento positivo. ${ }^{14}$ Sin embargo, según Smith, tomar conciencia de la simpatía no es cuestión de sumar unos sentimientos a otros, pues se trata de un nuevo sentimiento, independiente tanto del sentimiento original del otro como de nuestra simpatía por éste. Es un sentimiento de segundo orden, podríamos decir, en respuesta a la concordancia que se produce entre los sentimientos de primer orden de ambas partes, más que a los objetos a los que tales sentimientos se dirigen.

Además, una pasión simpatética, para Smith, no es una "imagen refleja de la pasión principal", como afirmaría Hume. En tal sentido, Hume asume la presencia de su propia postura acerca de la simpatía en los postulados de Smith, como si este último también fuera un teórico del contagio que da por hecho que los sentimientos simpatéticos reflejan de forma directa los sentimientos del otro. Para Smith, nuestra simpatía surge al imaginarnos en la situación del otro, pero no existe certeza de si nos sentiremos inmersos hipotéticamente en ella, tal cual como se siente el otro. Si el otro se muestra malhumorado y se queja constantemente, tal vez no sintamos ninguna clase de simpatía por él. Pero si, en efecto, nos sentimos exactamente igual al otro, se presenta un nuevo elemento en la situación - la armonía surgida entre ambas partes - respecto del cual, si somos conscientes de ello, también gene-

${ }^{14}$ David Raynor, "Adam Smith and the Virtues", en Adam Smith Review 2 (2006). Véase mi respuesta a Raynor en la misma edición de Adam Smith Review. 
rará sentimientos. El sentimiento de aprobación es mi reacción a aquel nuevo elemento en la situación, distinto a los sentimientos del otro y distinto también de mis sentimientos simpatéticos por el otro. No existe razón alguna por la cual este nuevo sentimiento deba adoptar el carácter de los sentimientos originales cuya concordancia genera. Y en los casos donde los sentimientos originales son dolorosos, afirma Smith, no ha de ser así; será, más bien, "siempre agradable y placentero". ${ }^{15}$

Resta preguntarse si tal premisa es cierta. Smith indica que la simpatía "alivia el dolor al transmitir al corazón del otro prácticamente la única sensación agradable que, en ese momento, éste es capaz de aceptar" (TMS 14, I.i.2.3); en un funeral, por ejemplo, nos reconforta el dolor empático de nuestros amigos, a pesar de que continuemos sufriendo la pérdida. Además, más allá de lo que Hume pueda haber pensado, en ocasiones un hospital sí puede resultar más divertido que un salón de baile. Si mi ánimo se encuentra sombrío y prefiero estar entre quienes sufren en lugar de intentar tomar parte en situaciones de júbilo, o si desapruebo la ocurrencia de un baile - en cuanto distracción frívola ante alguna crisis mundial a la cual considero que la gente debiera prestar atención-, entonces perfectamente podría pasar la tarde en un hospital y no en un salón de baile. En general, el júbilo que desaprobamos tiende a deprimirnos y enfadarnos, y el dolor que aprobamos tiende a infundir en nosotros al menos una pizca de placer; por medio de la solidaridad compartimos el dolor con quien lo siente. ${ }^{16}$

Según mi opinión, es precisamente ese sentido de solidaridad lo que Smith busca hacer notar. Darnos cuenta de que la empatía mutua es siem-

15 Ello no implica desconocer que este sentimiento "siempre agradable y placentero" pueda ser vago y resultar anulado por los sentimientos dolorosos de primer orden, de ser el caso, ante los cuales responde. Esto es, presuntamente, lo que ocurre en ceremonias funerarias y otras ocasiones trágicas. Es decir, experimentamos cierta cuota de placer al constatar la existencia de sentimientos mutuamente armónicos, pero tal placer resulta superado por el duelo, por lo tanto, nuestro ánimo general se vuelve sombrío (véase $T M S$ 14-15).

${ }^{16}$ No caben dudas de que esta pizca de placer generada por una concordancia de sentimientos puede verse eventualmente superada por la ira o el dolor a través del cual llegamos a sentir dicha concordancia. Pues eso es lo que el propio Smith afirma en la frase recién citada - la simpatía "alivia" el dolor, pero no lo elimina$y$, de hecho, enfatiza que preferimos simpatizar con el júbilo que con el pesar; de ahí nace, entre otras cosas, nuestra perniciosa tendencia a simpatizar más con el rico que con el pobre (TMS 51-2, 61-2). 
pre agradable, pues, a través de ella, percibimos nuestra pertenencia a una comunidad de seres humanos. Descubrimos que nuestros sentimientos personales son característicos del entorno social en el que nos desenvolvemos y ello nos reconforta y anima. No queremos parecer extravagantes por lo que sentimos; en ocasiones se nos cataloga de esa forma y ello nos preocupa. Si un amigo o colega desaprueba nuestra ira, nuestra autocompasión, el gozo que sentimos por nuestros logros, incluso nuestro buen humor, tememos sentirnos apartados o que algo no haya ido bien en nuestra conformación emocional. Por lo tanto, nos alivia descubrir que otros sí comparten lo que sentimos. ${ }^{17}$ Comprender que otros sienten de la misma manera en que nosotros sentimos nos da señales de nuestra aceptación en la comunidad humana y eso resultará siempre placentero. ${ }^{18}$

Desde este punto de vista, nuestra humanidad común es más sentida que razonada, ya que consiste en ciertos sentimientos compartidos o cierta disposición a compartir sentimientos específicos y lo reconocemos por medio del sentir más que del pensar. Pero, tal vez, esto sea una dicotomía demasiado estricta. La empatía smithiana depende, como ya lo hemos señalado, de un proceso reflexivo por medio del cual nos ponemos a nosotros mismos en la situación de un tercero, lo que exige algún grado de razonamiento de nuestra parte. Pero la humanidad compartida de naturaleza sentimental que aquí emerge sigue siendo diametralmente distinta a la humanidad compartida de carácter racional propia de un Platón o de un Kant. La razón por sí sola no constituye la humanidad compartida que plantea Smith ni nos hace conscientes de

17 John Steinbeck opina a este respecto: "Somos animales solitarios e intentamos la vida entera ser menos solitarios. Uno de los métodos más antiguos al que recurrimos para ello es narrar alguna historia esperando que el oyente nos reafirme diciendo: Así es o, al menos, así es como lo siento. No estás tan solo como pensabas". Citado en Writers at Work 02, editado por G. Plimpton a partir de las entrevistas en el Paris Review (Harmondsworth: Penguin, 1977), 183.

${ }^{18}$ Smith jamás señaló directamente que la experiencia de empatía mutua constituyera una afirmación de nuestra humanidad común, pero tal lectura concuerda con los hechos fenomenológicos, según creo, y explica por qué esta experiencia sería siempre agradable. También da sentido a la reiterada afirmación de Smith en cuanto a que, si luchamos por lograr cierta empatía mutua con un tercero, es preciso que nos veamos a nosotros mismos como "uno más de la multitud en ningún sentido mejor que los otros" (TMS 83, II.ii.2.2; véase también 137). ¿Por qué es la igualdad humana presuposición o consecuencia del logro de la empatía mutua? Pues porque la empatía mutua capta aquel aspecto de nosotros mismos en el cual somos todos iguales, esto es, la forma en la que respondemos de manera emocional. 
ella. Tampoco esta humanidad común smithiana es puramente biológica ni un postulado religioso dependiente de un alma otorgada por Dios.

$\mathrm{Y}$ si hay algo que distingue a la humanidad común smithiana de estas alternativas es el grado en que ella considera, precisamente, lo que nos hace diferente del otro. Como ya hemos visto, en la empatía smithiana somos conscientes de que la persona con la cual empatizamos tiene una perspectiva propia a partir de la cual experimenta lo que siente. Si dicha persona tiene, a su vez, consideración de uno, también será consciente de nuestra peculiar perspectiva. El que dispongamos de perspectivas distintas y, por tanto, seamos capaces de diferir es, precisamente, uno de los rasgos que compartimos y disfrutamos compartir. En otras palabras, lo que me une, sentimentalmente hablando, con el resto de la humanidad no es sólo una disposición a ciertos sentimientos en ciertas circunstancias específicas, sino también la habilidad de ser consciente de tales sentimientos a partir de un punto de vista particular. Únicamente porque tenemos distintos puntos de vista es que nos preocupan nuestras diferencias con los demás; sólo porque nos preocupan tales diferencias es que disfrutamos descubrir que no somos tan distintos a los demás después de todo. Pero ese descubrimiento, una vez explícito, equivale a darnos cuenta de que somos similares aunque distintos, de que conservamos nuestra singularidad incluso teniendo reacciones semejantes. En la empatía smithiana se integran dos ideas fundamentales: 1) "No obstante todas nuestras diferencias, seguimos compartiendo iguales reacciones" y 2) "No obstante todas nuestras similitudes, seguimos siendo personas distintas". Ambos criterios son fuentes de placer y el placer distintivo de la empatía smithiana lo consideramos precisamente en virtud de esta combinación. Ellos perfilan, en conjunto, el tipo de humanidad común en la que nos gusta participar.

En consecuencia, la concepción sentimental de Smith sobre la humanidad es, al mismo tiempo, una concepción perspectivista. Ser humano, para Smith, no depende de ser racional o poseer un alma otorgada por Dios, sino de desarrollar y sostener una perspectiva, un punto de vista propio: ese entramado de opiniones y actitudes que responde a las situaciones que hemos vivido en el pasado y que moldea la manera en que viviremos las situaciones futuras. Y ya que las situaciones que yo he vivido difieren de aquellas vividas por el otro, mi perspectiva diferirá de la suya. Lo que compartimos, lo que nos hace humanos y 
nos diferencia de los animales ${ }^{19}$ es el hecho de tener una perspectiva. También podemos penetrar en la perspectiva del otro por medio de la empatía; en efecto, llegamos a reconocer que tenemos una perspectiva propia sólo cuando comprendemos de manera empática que los demás también tienen la suya. De esta forma, entendemos que formamos parte de una humanidad común tanto gracias a nuestra capacidad de empatía como al hecho de tener una perspectiva propia; no es posible separar ambos aspectos. Desde este punto de vista, ser una criatura humana significa tener una perspectiva y mantenerla, pero sólo es posible hacerlo si tomamos parte en el proceso de empatía smithiana. Somos, al mismo tiempo y de igual forma, seres empáticos y dueños de una perspectiva propia.

4.

¿Qué es una perspectiva? Una perspectiva es un sistema relativamente lógico y continuo de opiniones y actitudes que se ha formado en respuesta a acontecimientos ocurridos en el mundo que nos rodea. Contrasta con una simple confusión de emociones, con emociones pasajeras que se desvanecen al instante y con emociones desconectadas del mundo exterior, quizás ocasionadas por algo en nuestro entorno, pero sin representar en absoluto la causa que las ha originado. Una perspectiva también difiere de aquellas creencias a las que hemos llegamos sin intervención de nuestros sentimientos. Las creencias que adoptamos por "mero entendimiento" no constituyen una perspectiva; tampoco una colección de sentimientos arbitrarios a la Hume que no representan nada más allá de sí mismos. Una perspectiva es una consideración subjetiva del mundo, pero, lamentablemente, muchos filósofos no ofrecen ninguna explicación del funcionamiento mental que la genera.

${ }^{19}$ Existirá, a lo sumo, un grado muy atenuado de perspectiva en un perro o en un chimpancé - es decir, un sentido integrado del mundo que es moldeado por la historia y que sabe por sí mismo que así ha ocurrido - y ningún grado posible de ella en un pez o en una lombriz. Frans de Waal ha demostrado que los chimpancés sí exhiben algunas de las habilidades involucradas en la empatía, pero nada que se parezca a la capacidad de estar pendiente de la vida de otros o a una manera de hacer las cosas que pudiera equivaler al reconocimiento de cualquier clase de perspectiva. 
Adam Smith sí lo hace. Al explicar su concepción de la simpatía, el filósofo escocés entrelaza emociones con opiniones. En efecto, su visión de la forma en que aprobamos y desaprobamos distintos sentimientos o pasiones también depende de que las veamos como opiniones, es decir, como adecuadas o no a sus objetos de interés. "Aprobar las pasiones del otro... como adecuadas a sus objetos", afirma Smith, "equivale a simpatizar enteramente con ellas" (TMS 16, I.i.3.1). Smith ilustra este punto con una serie de ejemplos: compartir el resentimiento del otro, sintonizar con su pesar, admirar el mismo poema o la misma pintura que el otro admira o reír con la misma broma que divierte al otro. Estos ejemplos combinan reacciones morales con reacciones estéticas, sentimientos que responden a hechos con sentimientos que responden a acciones, y sentimientos que perduran por un tiempo considerable - como el resentimiento o el pesar-con sentimientos momentáneos de admiración o hilaridad. En el siguiente párrafo, Smith compara lo que implica compartir emociones y compartir opiniones: "Aprobar las opiniones del otro equivale a adoptar tales opiniones", lo que "también ocurre a la hora de aprobar o desaprobar sentimientos o pasiones ajenas" (TMS 17, I.i.3.2). Y, en el siguiente capítulo, el filósofo lleva nuestras reacciones compartidas al terreno del arte, la ciencia y la filosofía, así como aquéllas que manifestamos ante el dolor, la dicha y la indignación. En resumen, para Smith nuestras vivencias intelectuales y emocionales forman parte de una misma pieza, todas representan el mundo que nos rodea y todas pueden variar de acuerdo con los acontecimientos que ocurren en él, sumándose a la manera general en que lo experimentamos. Lo anterior ayuda a explicar cómo es que Smith habla, más adelante en el libro, de la diferencia que existe entre el considerar lo que uno sufriría estando en la situación de otro y el "considerar lo que uno debiera sufrir si efectivamente fuera el otro... intercambiando con él su persona y su carácter". En efecto, cada uno de nosotros tiene "una persona y un carácter", una perspectiva.

5.

Como ya habremos notado, existe una conexión entre involucrarse en una empatía de tipo smithiano y ser consciente de las diversas perspectivas existentes, incluso de las propias. Sólo si soy capaz de 
penetrar en la perspectiva del otro, puedo darme cuenta de que tengo una perspectiva propia. Pero me atrevería a afirmar que dicha conexión entre empatía y perspectiva va más allá aún, pues ni siquiera podríamos contar con una perspectiva propia a menos que fuéramos capaces de ingresar de manera empática en la perspectiva del otro. En tal sentido, podríamos decir que la conexión entre empatía y perspectiva es metafísica y no solo epistemológica. Intentaré defender este argumento por medio de un problema que explica la empatía tal como la he presentado hasta ahora.

He dado por hecho que existe una clara distinción entre la simple empatía y la empatía perspectivista o smithiana. La mayor parte de los autores también lo dan por hecho. Peter Goldie, por ejemplo, distingue entre empatizar e imaginarse en el lugar del otro, donde la primera opción implica imaginarse a uno mismo como si fuera el otro en su particular situación y la segunda nos exige imaginar cómo nos sentiríamos siendo nosotros mismos en su caso. ${ }^{20}$ Smith parece trazar similar distinción al afirmar, según hemos constatado, que existe una diferencia entre sumergirnos en la situación del otro como nosotros mismos y hacerlo desde "la persona y el carácter" del otro.

Tales distinciones parecieran ser intuitivamente factibles, aunque suponen que es posible contar con perspectivas estables y claramente delineadas, independientes de la empatía. Quiero ahora cuestionar esta suposición. ¿Existe tal cosa como "mi perspectiva" y "tu perspectiva" independientes de la empatía? Consideremos lo que significa para mí penetrar en la situación del otro siendo yo mismo. Supongamos que intentamos imaginarnos en la situación de una persona de raza negra que ha sido objeto de amenazas raciales o de una persona pobre que ha perdido o la han engañado con diez dólares. ¿Puedo sumergirme en la

${ }^{20}$ En realidad, la explicación que ofrece Goldie sobre la opción de imaginarse en el lugar del otro no es del todo clara, quizás precisamente por las razones que a continuación planteo. Goldie se niega a aceptar el imaginarse a un yo, sin adornos, en la situación del otro como ilustrativo del fenómeno - de ahí su insistencia en que el caso de Crane y Tees no es ejemplo de empatizar ni de imaginarse en el lugar del otro (The Emotions, 200) - , afirmando que más bien implica una combinación de "ciertos aspectos de mi caracterización" con "ciertos aspectos de la caracterización del otro" (ibídem). Sin embargo, no nos explica cómo configurar el planteamiento ni por qué razón no deberíamos considerar una proyección de nosotros mismos en la situación del otro como ejemplo de esta clase de imaginación. 
situación del otro en grado suficiente sin imaginar cómo sería ser el otro en dicha situación? Si sufro una amenaza o insulto racial, es improbable que ello provoque en mí las consecuencias prácticas o el impacto emocional que la misma amenaza o insulto generaría en una persona de raza negra; y si soy privado de 10 dólares, mi vida $-\mathrm{y}$, por consiguiente, mi estado emocional - sufriría un daño mucho menor al que una pérdida similar produciría en una persona de extrema pobreza. Incluso para entrar en la situación del otro adecuadamente, debo transformarme en el otro en un grado suficiente, ya que no seré capaz de imaginarme en su lugar si sigo siendo completamente "yo" en mi imaginación. ${ }^{21}$ Además, no existe un límite claro sobre cuánto de la situación del otro debemos adoptar para empaparnos correctamente de ella. Las consecuencias generadas por el retraso de un vuelo en una persona impaciente son diferentes a las provocadas en alguien de carácter más calmado, ${ }^{22}$ los efectos de un contratiempo en la vida de una persona con un ego frágil son distintos de aquellos en alguien con una gran confianza en sí mismo. Lo que cada situación significa en la vida de una persona — qué implica cada situación para ella - no puede aislarse de lo que la persona

${ }^{21}$ Ver también Bence Nanay, "Adam Smith's Concept of Sympathy and its Contemporary Interpretations", en Essays on the Philosophy of Adam Smith, editado por V. Brown y S. Fleischacker (Londres: Routledge, 2010): "Una cuestión crucial a preguntarse sobre la interpretación que hace Adam Smith de la simpatía es qué queremos decir con 'la situación del otro' cuando hablamos de imaginarnos a nosotros mismos en una situación ajena" (91). Entender cómo el otro podría sentirse cuando es, por ejemplo, atacado requerirá que consideremos factores tales como si "el otro sabe algo sobre el atacante que pudiera significarle un mecanismo de defensa (por ejemplo, por medio del chantaje)". Por ende, la "situación del otro" no sólo incluirá "factores psicológicos, sino también epistémicos" y físicos. También incluirá factores afectivos. Si una persona ha endurecido su carácter tras participar en combates militares, tomará los ataques de terceros con filosofía y reaccionará de modo muy distinto a otra persona que ha sido resguardada del peligro su vida entera. Su situación también incluirá factores culturales. Alguien criado en una cultura que valora el enfrentamiento físico y humilla a todo el que huye ante el menor peligro, reaccionará de manera muy distinta ante un ataque que alguien criado bajo la premisa de que no merece la pena correr riesgos innecesarios.

${ }^{22}$ Un ejemplo que el propio Goldie emplea: "Si me imagino yo mismo perdiendo el avión (asumiéndome, como lo hago, como una persona irascible), ello deja a quien ha sufrido la experiencia como enfadado y frustrado. Si la empatía en igual caso proviene, digamos, de la Madre Teresa de Calcuta, pues se asumirá que el protagonista de la historia ha reaccionado con serenidad" (The Emotions, 201). 
siente al respecto ni estos sentimientos pueden separarse de su historia previa, incluidos sus antecedentes psicológicos. En cada una de las diversas experiencias que vivimos participa nuestra particular disposición para reaccionar emocionalmente ante ellas y la historia de vida que ha configurado tal disposición. En consecuencia, no podemos imaginarnos verdaderamente en los zapatos del otro sin empatizar, en cierta medida, con él; así no es posible vislumbrar claramente la distinción que hace Goldie, o la que paralelamente presenta Smith.

De igual forma, no es posible imaginar cómo sería ser otro sin también imaginar cómo sería estar en sus zapatos. ¿Cómo puedo imaginarme qué es ser otro sin imaginarme cómo sería ocupar la posición histórica y social del otro, o pasar a través de sus experiencias? ¿Qué somos sino una sumatoria de todo eso? Al fin y al cabo, nuestras características — una actitud jovial o cínica ante la vida, una contextura atlética o descuidada, respeto o irrespeto por nosotros mismos, encanto o irritabilidad, facilidad o dificultad para abordar el pensamiento abstracto- son, principalmente, resultado de nuestra posición en la vida, de nuestras experiencias.

Sin embargo, si intentamos adoptar por completo lo que caracteriza al otro, sus experiencias de manera integral sin dejar nada de nosotros mismos, ya no estaremos empatizando en lo absoluto, sino meramente intentando fundirnos con el otro. Por lo demás, fundirnos con el otro es, naturalmente, imposible, ${ }^{23}$ y ponerlo como ideal impide ver claramente

${ }^{23}$ Pero Goldie (siguiendo los pasos de Max Scheler) parece pensar distinto al respecto. En la "identificación emocional", señala, "el sentido de identidad propio en cierta medida se funde con el sentido de identidad del otro, por lo tanto, se produce una suerte de liberación de límites entre la identidad cognitiva y la sensorial". Goldie admite que "no es fácil explicar en qué consiste la identificación emocional", pero sí menciona la "identificación con un tótem, una experiencia mística exultante, la identificación de una madre con su hijo" y la profunda unión que experimenta una pareja en el "acto sexual realizado por amor" como ejemplos de ella (The Emotions, 193-4). Evidentemente, las personas suelen decir que se "funden" con el otro, que "abandonan" su propio yo en tales circunstancias, pero no veo razón para considerar dichas expresiones del lenguaje mucho más que una manera hiperbólica de describir un cierto tipo de dicha o estado de alerta natural o la mera ilusión de "convertirse" en una persona diferente (en un antepasado o en un amante, por ejemplo; en este último caso, no es infrecuente que la ilusión se desvanezca por completo apenas ocurrido el acto sexual "realizado por amor"). Cualquiera sea el caso, es imposible otorgar a toda esta imaginería algún sentido literal adecuado, pues resulta innegable que la conciencia humana se presenta en manifestaciones in- 
que somos nosotros mismos quienes hacemos trabajar la imaginación, así como impide ver la necesidad que tenemos de recurrir a nuestras propias experiencias y sentimientos para abrirnos paso en las experiencias y sentimientos del otro. Evidentemente, podría limitarme a emular lo que el otro dice o hace sin siquiera intentar sentir lo que siente, pero ello ya no sería una manera de hacer que mi propio yo se sumerja, a partir del sentimiento, en la situación del otro. En ninguna de estas opciones me puedo imaginar a mí mismo en la perspectiva o el carácter del otro, sino que pierdo de vista por completo a mi propio yo y, por consiguiente, pierdo la habilidad de generar sentimientos personales por la situación del otro. ${ }^{24}$

dependientes y específicas y que nunca será posible que nos fundamos con la mente de otro de la manera en que dos sustancias químicas se funden para formar una nueva sustancia. Naturalmente que existen escenarios de ciencia ficción en los cuales las mentes efectivamente se funden o mezclan entre sí, pero estos pueden darnos la errada impresión de que es efectivamente posible fundirnos con otra persona. Es probable que se presenten dificultades lógicas y no sólo físicas en escenarios como ésos.

${ }^{24}$ Goldie, una vez más, parece no estar de acuerdo al afirmar que, idealmente, no deberíamos incorporar "ningún aspecto del yo" en el proceso imaginativo de la empatía y abandonar nuestra propia perspectiva ("caracterización" en términos del propio autor) todo cuanto sea posible (The Emotions, 202). Sin embargo, si me olvido por completo de mí mismo, no seré capaz de ingresar en la perspectiva del otro. Incluso, recurriendo a uno de los ejemplos del propio Goldie, si yo —una persona de clase media, sin tendencia heroica alguna, que jamás ha estado en una batalla - deseo imaginarme a mí mismo en la situación del príncipe Andrei, de la novela de Tolstoi, enfrentado a la batalla de Schön Graben, deberé apelar a todos los momentos en los cuales he sentido un destello de bravura o de gracia aristocrática en mi vida. De otro modo, no lograré entender por qué la elegante calma del príncipe Andrei se adecúa tan bien a su carácter; no seré capaz de percibir la pertinencia de dicho momento en la novela. Goldie compara la empatía con la actuación en el estilo promovido por la escuela Stanislavski (The Emotions, 178). Sin embargo, dicho método es famoso por instar a los actores a encontrar algo en su interior por medio de lo cual puedan aproximarse a los sentimientos y rasgos de sus respectivos personajes. Según mi opinión, lo que Goldie llama "empatizar" e "imaginarse en el lugar del otro" son categorías pertenecientes a un mismo espectro que no se oponen drásticamente una a la otra. Dejo más de mi propia perspectiva ("caracterización") atrás y asumo más de la perspectiva del otro al empatizar, y dejo menos de mi propia perspectiva atrás y asumo menos de la perspectiva del otro al imaginarme en su lugar. No se trata de dos situaciones de naturaleza distinta, y, ciertamente, nos movemos con soltura dentro de este espectro cuando buscamos entender a los otros y a nosotros mismos. Es por eso que la empatía smithiana, tal como yo la interpreto, acoge tal espectro como un todo y no uno u otro de sus extremos. 
Si intento fundirme con el otro ciertamente no podré lograr lo que Smith considera que buscamos por medio de la proyección imaginativa, es decir, no seré capaz de adoptar una posición desde la cual evaluar los sentimientos del otro como apropiados o inapropiados para su situación específica. Con el fin de evaluar correctamente los sentimientos como apropiados o inapropiados a una situación en particular, es preciso tomar distancia del punto de vista de la persona que experimenta tales sentimientos; es necesario abstraerse de los factores presentes en el estado emocional del otro que lo hacen reaccionar demasiado apasionadamente o con escasa pasión, o que lo hacen reaccionar - tal como en ciertos ejemplos que el propio Smith ofrece- como un lunático, un niño o un “impertinente y rudo" estúpido (TMS 12, I.i.1.10). Es intrínseco a la capacidad empática, más allá de su relación con el juicio moral, que controlemos dicha distancia con respecto al otro. Si el estúpido, el lunático o el de comportamiento infantil hubieran sido plenamente conscientes de lo que hacían, muy probablemente habrían reaccionado de manera distinta a como lo hicieron. Podrían incluso haber intentado cambiar su actitud mientras se los observaba; al menos las personas con mayor control de sí mismas suelen intentarlo. Juzgamos equivocadamente a los demás si damos por sentado que son esclavos de sus perspectivas, si no admitimos lo mucho que se esfuerzan por romper el molde de los límites de la conciencia del sí mismo que sus hábitos o su historia personal les han impuesto. Todos nosotros, de manera constante, intentamos vernos a nosotros mismos como los demás nos ven y cambiamos nuestro comportamiento en respuesta a dicha visión. Cuando experimento alguna situación frustrante, reúno opiniones de mis amigos para saber si estoy sobrerreaccionando ante ella o no reaccionando con suficiente energía. Si consigo un logro inesperado, observo subrepticiamente a mi alrededor antes de determinar si debiera dar brincos de alegría o reaccionar con mayor modestia y expresarme en un tono más medido. $\mathrm{O}$ tal vez mi respuesta surja de un ejercicio de introspección sobre la manera en que considero que un espectador imparcial reaccionaría en iguales circunstancias. ${ }^{25}$ Todo esfuerzo que implique entendernos a nosotros mis-

${ }^{25}$ Evidentemente, en ciertas ocasiones reaccionamos de manera tan inmediata y con una pasión tan primitiva que ni siquiera consideramos lo que los demás podrían llegar a pensar de nosotros. Sin embargo, muy a menudo sí lo tomamos en cuenta y nuestro modo de reacción y nuestra disposición emocional son 
mos y transformarnos es parte integrante de lo que significa tener una perspectiva propia. Por lo tanto, quien quiera que se esfuerce por simpatizar conmigo no tendrá éxito en su misión si asume que cada mínimo detalle de lo que soy es totalmente inalterable. La empatía nos exige, por tanto, evitar congelar el punto de vista de las personas con las cuales empatizamos, evitar encapsularlas en una sola forma determinada.

Tampoco debemos asumir, al intentar entender de manera empática a alguien, que nuestras propias reacciones o puntos de vista son inalterables. Digamos que $\mathrm{A}$ es un sujeto mustio y sin carácter y $\mathrm{B}$, alguien decidido y audaz. A observa a B adoptar una postura heroica ante determinada dificultad y piensa: "Yo jamás tendría el coraje de hacer eso”. ¿Pero puede realmente A asegurar algo así de sí mismo? La sola admiración que siente por B sugiere la existencia de cierta motivación por ser como B es. Y si consigue penetrar de manera empática en las circunstancias y actitudes que le han dado a $\mathrm{B}$ el coraje que ha demostrado, no cabe duda de que logrará vislumbrar lo que debe hacer para lograrlo él también. En una futura situación similar, A perfectamente podría preguntarse: “QQué haría B en este caso?” y sencillamente hacerlo. Es preciso entender que nos tergiversamos a nosotros mismos si nos creemos incapaces de hacer esto o aquello. Por el contrario, siempre debemos asumir que el otro podría ser nosotros y nosotros ser el otro. Eso es lo que significa para los seres humanos ser capaces de considerar al otro e instalar la humanidad compartida que nos caracteriza en el corazón de tal capacidad. Pero entonces no existirá una frontera clara entre lo que significa ser yo en la situación del otro y ser el otro en dicha situación. Llegar a entender de la mejor manera posible quiénes somos es una meta en constante movimiento, una perspectiva cuyos contornos llegamos a comprender, a controlar, sólo en tanto tomamos parte en un

configurados por esta clase de interacción. Ello incluye, al menos hasta cierto punto, la manera en que manifestamos nuestras pasiones. Tolstoi lo ilustra con una precisión magistral: "Sentí deseos de salir corriendo tras él", dice Pòzdnyshev, loco de celos, sobre el músico amante de su esposa, "pero entonces pensé cuán ridículo puede verse salir corriendo tras el amante de la esposa en calcetines; naturalmente no quería parecer ridículo sino furioso. A pesar del terrible estado de histeria en el que me encontraba, nunca olvidé la impresión que podía causar en los demás y mi reacción fue parcialmente gobernada por ella". Ver "The Kreutzer Sonata", en Collected Shorter Fiction, vol. 2, traducido por L. y A. Maude y N.J. Cooper (Nueva York: Alfred A. Knopf, 2001), 318. 
proceso de constante empatía con la perspectiva del otro. No somos dueños de una perspectiva independiente de la empatía y nuestros intentos por empatizar modifican nuestra perspectiva. Nuestro yo está determinado, hasta donde existe, sólo por las relaciones empáticas con otros, las que fluctúan constantemente entre lo que tenemos en común y lo que nos diferencia.

Por lo tanto, distinguir entre imaginarme en la situación del otro e imaginarme siendo el otro oculta el grado en el que nuestras respectivas situaciones dependen de quiénes somos, el quiénes somos depende de nuestra situación y nuestras perspectivas incluyen un esfuerzo por ir más allá de sus limitaciones intrínsecas. Oculta, en pocas palabras, el grado en el cual, en el contexto de nuestras relaciones empáticas, intento verme a mí mismo como el otro y el otro intenta verse a sí mismo como yo. No nos fundimos uno con el otro, pero quién es cada cual depende inexorablemente de cómo vemos a los demás. ${ }^{26}$

6.

Esto nos lleva a la concepción de Smith acerca del yo, que — según pienso- él ve como una consecuencia del proceso de empatía. Para Smith, no tenemos un yo independiente de una perspectiva del mundo y no tenemos una perspectiva del mundo independiente de nuestras interacciones empáticas con los demás.

Para explicarme mejor: según Smith, tendemos a reflexionar sobre nosotros mismos, es decir, penetramos en nuestra propia perspectiva de manera empática, como si desde la perspectiva de un espectador imparcial se tratara, sólo después de percibir que es eso lo que los demás también hacen con nosotros:

${ }^{26}$ Creo concordar plenamente con Karsten Stueber en este punto: "[Los procesos naturales que conforman la empatía] deben ser entendidos no sólo como mecanismos que permiten reconocer que otros son 'como yo', sino que también permiten reconocerme a mí mismo 'como el otro'. Explícitamente y recurriendo a una terminología más tradicional, podría decirse que, en un contexto natural, entendemos nuestra subjetividad como una instancia de intersubjetividad interpersonal. También podría decirse que la naturaleza no resuelve el problema de las demás mentes. [Por el contrario], la naturaleza no tiene el problema que tienen otras mentes". Ver Stueber, Rediscovering Empathy (Cambridge: The MIT Press, 2006), 143. 
Nuestros primeros juicios morales se desarrollan con respecto del carácter y la conducta de los demás... Pero pronto comprendemos que las otras personas actúan de igual manera con nosotros. Entonces comenzamos a sentirnos ansiosos por saber cuánto merecemos su censura o su elogio, y si para ellos parecemos las mismas criaturas agradables o desagradables que ellos representan para nosotros. A partir de dicha reflexión, examinamos nuestras propias pasiones y conductas e intentamos dilucidar cómo podrían ser vistas por los demás, considerando cómo las veríamos nosotros mismos si estuviéramos en su situación. Nos suponemos espectadores de nuestro propio comportamiento e intentamos imaginar qué efectos éste produciría, bajo aquella luz, en nosotros mismos. (TMS 112, I.ii.1.5)

Por ende, la noción que tenemos de nosotros mismos surge, en primera instancia, de nuestra respuesta a la forma en que los otros nos ven. Incluso Smith menciona de manera explícita que sólo podemos arribar a esta noción dentro de la sociedad y desde la sociedad:

Si fuera factible que una persona creciera hasta alcanzar la edad adulta en algún lugar solitario, totalmente incomunicada de otros seres de su misma especie, dicha persona no estaría en condiciones de reflexionar sobre su propio carácter... ni sobre la belleza o deformidad de su propia mente o la belleza o deformidad de su propio rostro. Todos éstos son objetos que no podrá apreciar fácilmente, que en forma natural no tendrá en cuenta y con respecto a los cuales no contará con espejo alguno para estudiar. Introducid a dicha persona en la sociedad y tendrá de inmediato el espejo del que antes carecía. (TMS 110, I.i.3)

Una persona completamente "ajena a la sociedad", señala Smith, prestaría atención sólo a "los objetos de sus pasiones, a los cuerpos externos que le generan placer o dolor”; pero jamás se le ocurriría prestar atención a las "pasiones en sí mismas, a las dichas o dolores que tales objetos excitan" (ibídem). Sin el espejo de la sociedad, ni siquiera nos daríamos cuenta de que tenemos un yo.

Esto, sin embargo, no trasmite el punto con suficiente fuerza. Sin el espejo que nos brinda la sociedad, no sólo seríamos inconscientes de que poseemos un yo, sino que ni siquiera tendríamos un yo. Desafortunadamente, la metáfora del espejo confunde. Tenemos un cuerpo 
antes de ver nuestra imagen reflejada en el espejo; el espejo nos permite conocer su existencia, y éste existe seamos o no conscientes de él. Sin embargo, en la teoría cartesiana y lockeana del yo, a partir de las cuales trabajaron los primeros filósofos modernos, éste no existe si no se es consciente de él. Según estos criterios, el yo es, por definición, algo que se refleja a sí mismo. ${ }^{27}$ Por lo tanto, el yo smithiano no puede sino existir hasta que es despertado por la sociedad a través del acto reflejo. La sociedad da vida al yo y, simultáneamente, brinda los estándares que guían sus actos más característicos de autorreflexión; actos que, para Smith, son primero y por sobre todo de autorreflexión moral. Smith responde a la deconstrucción que hace Hume del yo en el libro 1 del "Tratado sobre la naturaleza humana" de la misma forma en que lo hace Kant: instala la imagen de un yo continuo con propósitos morales. Pero Smith, a diferencia de Kant, considera la construcción social del yo como necesaria para este planteamiento moral. Por su parte, Hume concluye su capítulo sobre identidad personal sugiriendo que la identidad que atribuimos al yo, tal como la identidad que atribuimos a una iglesia que es reconstruida con un nuevo estilo, puede servir a objetivos sociales. ${ }^{28}$ Pero, para Hume, ello no hace más que evidenciar que el yo es

${ }^{27}$ Udo Thiel, en un genial y minucioso estudio, afirma que esta concepción esencialmente reflexiva del yo no es atribuible a Locke, pues éste define al yo en términos de conciencia y a la conciencia, en términos de conocimiento de primer orden de las cosas que no precisa incluir una reflexión de segundo orden sobre tal conocimiento. Ver The Early Modern Subject (Oxford: Oxford University Press, 2011), capítulo 3. Sin embargo, Thiel admite que usualmente se ha entendido que Locke identifica la conciencia con la reflexión; por ejemplo, a través de Leibniz, "quien sencillamente da por hecho que la conciencia es sinónimo de reflexión para Locke" (ibídem, 112). Pero si un estudioso tan sagaz de Locke como Leibniz lo interpretó de esa forma, es muy probable que Smith lo haya entendido también así y que, en una suerte de guiño a una tradición de pensamiento sobre el yo en su obra (según considero que efectivamente hacía, pues no ofrece largos análisis de su autoría al respecto), haya definido el yo de manera similar al postulado reflexivo. Sobre esta materia, agradezco a Ruth Boeker por haberme orientado en la lectura del trabajo de Thiel.

28 "De igual modo podría decirse, sin temor a violar las normas de corrección del lenguaje, que tal iglesia, que anteriormente fuera de ladrillo, se transformó en ruinas y que la feligresía la reconstruyó de piedra franca siguiendo los dictados de la arquitectura moderna. En este caso, ni la forma ni los materiales son los mismos, ni tampoco existe nada en común entre ambos edificios, salvo su relación con los feligreses, pero ello basta para que los denominemos de igual forma" (Hume, $A$ Treatise, 258). 
"mera ficción". Smith, muy por el contrario, señala que nada de ficticio existe en el yo. Se trata de un principio que no podemos obviar, del que no podemos pensar fuera o más allá de él, tan real como cualquier otra cosa que necesitemos postular.

A Smith tampoco le preocupa que dicho principio sea resultado de un proceso de construcción social: precisamente así es como surgen los principios, tanto en la ciencia como en la moral.

Pero en esta concepción del yo, construida con propósitos morales a partir de actos de empatía hacia otros, y hacia uno mismo como si fuera otro, uno no tendría un yo previo a los actos de empatía. Yo determino quién es el otro al distinguir su perspectiva de la mía y determino quién soy yo al distinguir mi perspectiva de la perspectiva del otro. Y lo que hago para concordar apropiadamente con el otro y conmigo mismo puede variar conforme avanzo en el curso de este proceso imaginativo e interpretativo. De ello resulta que no existirá ningún yo "pre-empático" natural al cual volcarme, con el fin de establecer una distinción entre imaginarme siendo yo mismo en la situación del otro e imaginarme siendo el otro, sino que tal distinción surgirá del proceso empático propiamente tal.

Siendo más preciso, llegaré a determinar quién soy yo y quién es el otro al contrastar nuestras perspectivas con las del espectador imparcial. El espectador imparcial es la pieza central del sistema moral de Adam Smith. Se trata de un mecanismo que, dice Smith, desarrollamos dentro de nosotros mismos ante el hecho de que los demás suelen juzgarnos a partir de visiones sesgadas o simple desinformación. Por el contrario, deseamos saber cómo nos vemos a los ojos de alguien que conoce todos los hechos relacionados con nuestro actuar y que no tiene motivos para decidir en favor o en contra de nosotros o de un tercero en el contexto de nuestra situación. Lo que el espectador imparcial apruebe o desapruebe establecerá, según Smith, el estándar de lo que nosotros debiéramos aprobar o desaprobar. Sin embargo, mi foco en este ensayo no es la teoría moral de Smith. Quiero enfatizar, en cambio, el rol que cumple el espectador imparcial en nuestra psicología, particularmente, en la interpretación que hacemos del otro y de nosotros mismos. El espectador imparcial nos informa qué pensaría o cómo se sentiría en una situación particular un ser humano común, "cualquiera", de forma en que si el otro no parece pensar o sentir de aquella manera, asumo que 
ve el mundo desde una perspectiva propia. Por otra parte, logro verme a mí mismo, de igual forma, como poseedor de una perspectiva propia por medio de las diferencias que es posible establecer con el espectador imparcial. Al mismo tiempo, el espectador imparcial también se construye a partir de la perspectiva propia de los diversos espectadores reales que nos encontramos en la vida, debidamente corregidos en sus sesgos y desinformación. No es posible hallar en esta postura una concepción estable y esencialista del yo humano; en su lugar, nos mantenemos permanentemente dando sentido a nosotros mismos y a los demás por medio de una suerte de triangulación entre la perspectiva propia, la perspectiva del otro y la perspectiva teórica del espectador imparcial. ${ }^{29}$

Ésta es, me parece, una visión tremendamente plausible. Conforme intento descifrar qué es peculiar en mi manera de comprender el mundo, voy notando que mis formas de reaccionar, por ejemplo, a la grosería o a disputas familiares son distintas a las del otro. Simultáneamente, llevo a cabo una comparación mental entre las reacciones de ambos y la reacción que "cualquiera" —un "cualquiera" vago que es reflejo de cualquier persona que conozcamos - podría tener ante tales comportamientos. También percibo las diferencias del otro conmigo y con ese "cualquiera" cuando intento descifrar la manera en que dicho otro interpreta el mundo. Supongamos que ese otro es un académico judío practicante como yo, que se mantiene siempre sereno y acepta sin reclamos cada vez que los demás académicos programan actividades en días de fiestas judías, mientras yo me irrito. Entonces pienso: “¿Por qué existe esta diferencia entre ambos? ¿Acaso mi colega es más generoso o estoico que yo y entiende sabiamente que no es posible esperar que el mundo cristiano en el que vivimos se acomode a nuestras necesidades específicas? ¿O será que es conformista o cobarde y no está dispuesto a

${ }^{29}$ Compárese con Goldie: "El carácter, el estado anímico, los pensamientos, los sentimientos, las expresiones, las acciones, los cambios corporales, las manifestaciones de emoción y las interpretaciones personales de alguien —así como nuestras propias emociones, estados anímicos y carácter- desempeñan una función en la tarea de comprender y explicar las emociones y la vida emocional de ese alguien a través de un relato que suele lograrse únicamente por medio de un complejo y cuidadoso proceso de tâtonnement dentro del círculo hermenéutico (la palabra francesa tâtonner significa sentir o proceder con cautela, de acuerdo a nuestro propio modo, lo que capta adecuadamente la tarea interpretativa tal como deseo describirla)" (The Emotions, 189). 
defender sus derechos?". En el mismo escenario, también me pregunto si mi indignación es señal de que me respeto a mí mismo y estoy dispuesto a alzar la voz por mi pueblo o es señal de simple cólera y autocomplacencia. ${ }^{30}$ Para resolver mis dudas, me pregunto: ¿Cómo reaccionaría un espectador imparcial? ¿Cuál sería la respuesta ante esta clase de situaciones de un "cualquiera" imparcial debidamente informado? De este modo es como el espectador imparcial guía el proceso de elaboración por medio del cual interpreto quién es el otro y quién soy yo; en tal sentido, me brinda normas y estándares para dicho proceso, un punto de referencia sobre la manera en que "las personas en general" sienten o actúan y con respecto al cual puedo reconocer y evaluar mis propias peculiaridades y las del otro. Al mismo tiempo, este "cualquiera" se encuentra, en sí mismo, en constante proceso de construcción, producto de cómo interpreto los muchos "tú" que encuentro en el camino y los muchos "yo" que imagino yo mismo ser.

Se trata de una compleja y dinámica concepción de la individualidad, pero también fenomenológicamente exacta y muy útil para efectos morales. Explica claramente cómo y por qué nuestra noción del yo se vincula con nuestra noción de quién creemos que deberíamos ser y cómo y por qué tendemos a intentar cambiar nuestro yo mientras buscamos entendernos. En este escenario, la individualidad no es mera ficción, como Hume arguye, sino más bien un componente necesario e insoslayable de nuestra moral y reflexión psicológica. Sin embargo, se trata de un elemento indeterminado y en constante cambio, además de un reflejo y una respuesta a nuestro entorno social.

7.

Me gustaría finalizar este análisis recurriendo a un punto de vista histórico más amplio. Si estoy en lo correcto respecto al vínculo que Smith establece entre empatía y perspectiva, además de la interpreta-

30 Compárese con Goldie nuevamente: "Las circunstancias no existen de manera impersonal, libres de interpretaciones para el intérprete. Si somos dicho intérprete, nuestra percepción de las circunstancias, la manera en que vemos las cosas, podría verse afectada por nuestro estado de ánimo, nuestras emociones y nuestra personalidad. Por lo tanto, tal aspecto también debe ser considerado como elemento integrante de este círculo hermenéutico" (The Emotions, 186). 
ción de nuestra humanidad en ese sentido, él fue uno de los primeros filósofos en estudiar un tema que ha sido central para la literatura, la cultura popular y la política desde entonces.

El siglo XVIII es notable por su énfasis tanto en la noción de simpatía como en la de tener perspectiva. La crucial importancia que tuvo la simpatía en el pensamiento moral de esa época es por todos conocida. Lynn Hunt y Thomas Laqueur han demostrado el modo gravitante en que ésta configuró no sólo la filosofía moral, sino que también el pensamiento moral del quehacer cotidiano y las ideas que derivaron en los movimientos promotores de la abolición de la esclavitud y en la proclamación de los derechos humanos. Laqueur señala que el relato humanitario tan propio de este siglo —ofrece como ejemplos el realismo literario y los informes clínicos y autópsicos - inspiró los cambios políticos de la época, al hablar, "con pleno detalle, sobre los pesares y la muerte de las personas comunes, demostrando asimismo las cadenas causales que vincularían las acciones del observador de tales situaciones con el sufrimiento de quien las padece". ${ }^{31}$ Hunt se pregunta si puede ser "mera casualidad que las tres principales novelas de identificación psicológica del siglo dieciocho _Pamela (1740) y Clarissa (1747-8), de Richardson, y Julie (1761) de Rousseau - fueran todas publicadas en el período inmediatamente anterior a la aparición del concepto "derechos del hombre". ${ }^{32}$ La historiadora también nos brinda un pormenorizado análisis sobre la manera en que el arte y la música del siglo XVIII tuvieron como objetivo despertar la simpatía entre sus observadores y oyentes. Y la idea de que la simpatía - y no el que todos compartamos la facultad de la razón o la noción de que fuimos creados a imagen de Dios - sea la principal fuente de nuestra habilidad para ver a los demás seres humanos como semejantes es nueva en este período.

Un antecedente menos atendido, pero implícito en lo que Laqueur y Hunt señalan, es que el siglo XVIII también fue testigo del surgimiento o descubrimiento de la idea de la perspectiva. Hunt describe cómo las personas se maravillaban ante la habilidad con que Richard-

${ }^{31}$ Thomas Laqueur, "Bodies, Details, and the Humanitarian Narrative" en The New Cultural History, editado por Lynn Hunt (Berkeley: University of California Press, 1989), 176-177.

${ }^{32}$ Lynn Hunt, Inventing Human Rights (Nueva York: WW Norton, 2008), 39. 
son sumergía a sus lectores en los mundos que creaba, "produciendo la impresión de que el lector estaba presente" en estos mundos, y cómo Rousseau abrazó el hecho de que novelas nos invitan a vivir de forma vicaria en un "estado que no es el nuestro". ${ }^{33}$ Pero esto es un llamado a sumergirse en la perspectiva del otro. Las novelas nos abren la puerta a mundos o estados subjetivos distintos al propio; nuestro mundo objetivo visto por ojos de personas diferentes a nosotros. Es así como ingresamos en la cabeza de una Moll Flanders de Defoe, de una Pamela de Richardson o de una Julie de Rousseau, tal como más tarde lo haríamos en la de un Pip de Dickens, de un Pierre Bezukhov de Tolstoi o en la de los apesadumbrados Buddenbrook de Thomas Mann. Esta inmersión en la mente de otro, esta apreciación de su punto de vista psicológico, con lujo de detalles, es la especialidad de los novelistas y algo muy poco frecuente de hallar en la literatura antigua o medieval. Es bien sabido que la novela es un invento del siglo XVIII y su aparición permitió el desarrollo de un nuevo tipo de identificación sentimental. ${ }^{34}$ Pero esta identificación es inseparable de una nueva apreciación de las diferencias subjetivas que existen entre las personas y el grado en el que nuestros rasgos subjetivos se fusionan en un todo con características propias: la perspectiva. Esto equivale, qué duda cabe, a un nuevo "yo". Consideremos, en particular, las primeras novelas de carácter personal. Sólo logramos entrever el mundo interior de personajes como Yago o Hamlet por medio de sus monólogos, pero no estamos invitados a ingresar en su mundo subjetivo de manera holística o a considerar en qué forma sus pasiones y actitudes se suman a un todo subjetivo. En la literatura temprana, la primera persona solía ser un yo ejemplar que hablaba en nombre de todos. La primera persona del Libro de los salmos, de las Cartas de San Pablo o de las Confesiones de San Agustín apunta a representar los anhelos o las travesías religiosas de cualquier ser humano, y nosotros estamos destinados a vernos reflejados en ella. Por el contrario, la primera persona de obras como Grandes esperanzas, de Dickens, o Memorias del subsuelo, de Dostoievski, es un ser humano

${ }^{33}$ Ibídem, 54-5.

34 Ver Benedict Anderson, Imagined Communities (Londres: Verso, 1983), donde se hace notar la manera como estas identificaciones sentimentales, desarrolladas por medio de la lectura de novelas — también de periódicos-, dieron lugar al surgimiento del nacionalismo moderno. 
con características específicas, categóricamente distinto al lector, pero a cuyo mundo subjetivo éste está destinado a entrar.

No me parece una coincidencia que el énfasis en la empatía se haya producido simultáneamente con el énfasis en la diversidad de perspectivas, que luego fue seguida por la proclamación de los derechos humanos. La empatía y la perspectiva pertenecen la una a la otra. Adquiere importancia para mí empatizar con el otro sólo si el otro exhibe una perspectiva específica, que no me es posible captar recurriendo a la razón humana común y corriente o a una teoría general de la naturaleza humana. Sin embargo, logro entender que el otro tiene tal perspectiva y que incluso yo tengo tal perspectiva únicamente por medio de la empatía. Esta es la postura de Adam Smith, según yo la entiendo, aunque considero que Smith no hizo más que expresar con mayor claridad que sus antecesores una mirada que comenzaba a aparecer en la literatura, la política y la práctica moral de su época. ${ }^{35}$

En este sentido, Smith ayudó a desarrollar una concepción nueva, perspectivista de la humanidad, la que exhibe ciertas características muy interesantes. En primer lugar, asumo que la mayoría de nosotros siente que es "casi uno mismo" en la medida en que cuenta con una perspectiva propia del mundo. Afirmar que nuestro propio yo consiste en el uso de dicha perspectiva y en ser consciente de ella como tal parece mucho más válido que afirmar, como lo hace Kant, que mi razón pura equivale a mi propio yo. Por otra parte, señalar que mi propio yo consiste en la naturaleza divina de mi alma dice muy poco. Así seamos unos devotos teístas, es probable que no estemos seguros de lo que ello significa.

${ }^{35}$ Muchos atribuyen a Leibniz y no a Smith la idea de que todos y cada uno de nosotros tiene una perspectiva distintiva y holística. En efecto, la Monadología de Leibniz representa un tipo de perspectivismo donde cada mónada cuenta con una visión holística que difiere de manera esencial de la visión de las demás. Sin embargo, es notorio que las mónadas de la teoría de Leibniz "no tienen ventanas"; es decir, ninguna de ellas puede penetrar en la perspectiva de la otra. En tal sentido, sabemos que el otro representa un punto de vista específico por medio de una deducción racional a partir de su naturaleza divina — ningún ser perfecto tendría motivos para crear mónadas idénticas - y no a través de alguna clase de familiaridad directa con ese otro. Smith, por decirlo de algún modo, nos brinda mónadas "con ventanas". Pero esto es así porque la perspectiva de Smith ya no es una mera entidad racional. Es una entidad empírica - tal vez derechamente subjetiva - constituida, al menos, tanto por sentimiento como por razón. 
En segundo lugar, la noción de una perspectiva incluye la participación tanto de la razón como de los sentimientos; ésta se configura por la forma en que razono sobre la situación en la que me encuentro y por los poemas y los sistemas filosóficos que admiro, no sólo por sentimientos silvestres. Por lo tanto, dicha noción puede incluir en ella mucho de lo que es plausible en las visiones kantiana y humeana de la naturaleza humana. ${ }^{36}$ Puede otorgar igual importancia al razonamiento por sobre la coerción que los kantianos otorgan, ser tan igualitaria como lo es la visión kantiana y exigir la misma clase de respeto por los otros que exigen los kantianos. En efecto, al exigirnos a nosotros mismos respetar las diferencias existentes entre unos y otros, y no sólo nuestras características comunes, tal vez obtengamos mejores resultados que los kantianos a la hora de plasmar aquello a lo que aludimos cuando hablamos de respeto.

De igual modo, aunque la empatía smithiana no exige necesariamente una preocupación por el otro, es una condición elemental para prestar una atención respetuosa, sensible y matizada a los demás. De hecho, posiblemente prestaremos una atención deficiente si no lo hacemos a partir de la empatía smithiana, pues nos ocuparemos del otro sin considerar de manera consciente las diferencias existentes entre nuestra perspectiva y la suya. Es decir, si estoy en lo correcto con respecto a los vínculos existentes entre empatía, perspectiva y humanidad, sin Smith nos ocuparemos del otro de manera tal que no reflejará adecuadamente nuestra conciencia de su humanidad. Por el contrario, cuando una empatía smithiana de naturaleza perspectivista es la que guía nuestra preocupación por el otro, lo que hacemos es prestarle atención en cuanto ser humano específico y único, respetando tanto nuestras diferencias como nuestros rasgos comunes. Dicho a la manera kantiana: respetamos la humanidad en el otro y manifestamos la humanidad en nosotros. O, puesto en los términos usados por el kantiano moderno John Rawls, demostramos cuán seriamente nos tomamos lo que nos distingue unos de otros. ${ }^{37}$ Sin embargo, ni Kant ni sus seguidores han sido nunca com-

${ }^{36}$ Para algunas similitudes entre Smith y Kant, ver mi "Philosophy in Moral Practice: Kant and Adam Smith", en Kant-Studien 82, n. 3 (1991), y Leonidas Montes, Adam Smith in Context, (London: Palgrave Macmillan, 2004), 118-22.

37 John Rawls, Theory of Justice (Cambridge: Harvard University Press, 1971), 27. 
pletamente lógicos con respecto a tal distinción. Smith sí lo ha sido: su concepción perspectivista de la humanidad y la empatía que a ella subyace capta con maestría lo que consideramos más valioso de nosotros mismos, aquello que define y explica por qué somos, todos y cada uno, de un valor absoluto e intrínseco.

\section{BIBLIOGRAFÍA}

Anderson, Benedict. Imagined Communities. Londres: Verso, 1983.

Darwall, Stephen. "Empathy, Sympathy, Care”, Philosophical Studies 89, n. ${ }^{\text {2 }}$-3 (1998).

Fleischacker, Samuel. "Philosophy in Moral Practice: Kant and Adam Smith". Kant-Studien 82, n. ${ }^{\circ} 3$ (1991).

. "Sympathy in Hume and Smith: A Comparison, Critique, and Reconstruction". En Intersubjectivity and Objectivity in Adam Smith and Edmund Husserl, editado por C. Fricke \& D. Føllesdal. Múnich: De Gruyter, 2013.

Goldie, Peter. The Emotions. Oxford: Clarendon Press, 2002.

Hume, David. A Treatise of Human Nature, edición de L.A. Selby-Bigge \& P.H. Nidditch (segunda edición). Oxford: Clarendon, 1978.

Hunt, Lynn. Inventing Human Rights. Nueva York: WW Norton, 2008.

Kahneman, Daniel \& Amos Tversky. "The Simulation Heuristic". En Judgment under Uncertainty, editado por D. Kahneman, P. Slovic \& A. Tversky. Cambridge: Cambridge University Press, 1982.

Laqueur, Thomas W. "Bodies, Details, and the Humanitarian Narrative". En The New Cultural History, editado por Lynn Hunt. Berkeley: University of California Press, 1989.

Montes, Leonidas. Adam Smith in Context. London: Palgrave Macmillan, 2004.

_. "Self-Interest and the Virtues". En Adam Smith: His Life, Thought, and Legacy, editado por R. Hanley. Princeton: Princeton University Press, 2016.

Nanay, Bence. “Adam Smith's Concept of Sympathy and its Contemporary Interpretations". En Essays on the Philosophy of Adam Smith, editado por V. Brown \& S. Fleischacker. Londres: Routledge, 2010.

Plimpton, George, editor. Writers at Work 02, de la Paris Review. Harmondsworth: Penguin, 1977.

Rawls, John. Theory of Justice. Cambridge: Harvard University Press, 1971.

Raynor, David. "Adam Smith and the Virtues”. Adam Smith Review 2 (2006).

Smith, Adam. Correspondence of Adam Smith. Indianapolis: Liberty Fund, 1987.

. The Theory of Moral Sentiments, edición de D.D. Raphael \& A.L. Macfie. Oxford: Clarendon, 1976. 
Steinbeck, John. Entrevista en Writers at Work 02, editado por G. Plimpton. Harmondsworth: Penguin, 1977.

Stueber, Karsten R. Rediscovering Empathy. Cambridge: The MIT Press, 2006.

Thiel, Udo. The Early Modern Subject. Oxford: Oxford University Press, 2011.

Tolstoi, Lev. "The Kreutzer Sonata". En Collected Shorter Fiction, vol. 2, traducido por L. \& A. Maude \& N.J. Cooper. Nueva York: Alfred A. Knopf, 2001. EP 